\title{
Models and modelling
}

\author{
Jerzy Wolek \\ Institute of Biology, Pedagogical University of Cracow, Podbrzezie 3, \\ 31-054 Kraków, Poland \\ e-mail: jerzy.wolek0@neostrada.pl
}

\begin{abstract}
When searching for nature rules we encounter a fundamental difficulty: for technical reasons we are not able to investigate the whole Nature - we have to explore its sections i.e. empirical systems (structures). However, even then it might happen that the system is too complex and its comprehensive, direct investigation is impossible. In this case we can study the system by means of its abstract model e.g. a mathematical model.

Abstract models of empirical systems usually present simplified modelled systems, where simplification depends on different reasons, e.g. on the purpose of model construction or the state of our knowledge on a modelled system. As a rule we also exclude from the model those independent variables, whose influence on a dependent variable is insignificant. Simplification does not have to mean that the validity of the simplified heuristic model is lower than the validity of the same model before its simplification.

Some remarks refer to certain methodological problems associated with models and modelling, as well as scientific research performed with those tools.
\end{abstract}

Key words: modelling, model, mathematical model, methodology of science, scientific research.

\section{Introduction}

From the very beginning of our history a man observed the surrounding nature, he perceived that occurrence of some phenomena was characterized by a defined regularity, he learnt how to use these regularities in everyday life, forecasting the future phenomena. However, it took ages before the first foundation of scientific research was expressed and before the methodology of sciences, as we define it today, was developed. Galileo Galilei (1564-1642) and Izaak Newton $(1642-1727)$ were the first ones from whom the development of modern science could be dated. Galileusz was the first one who applied systematic experimentation, repeated measurements and a mathematical notation of obtained results in his studies (Werle 1992). In 1687 Newton published his work: Philosophiae naturalis principia mathematica that included advanced ideas of physics as a science. The most important, valid up to the present day, methodological meaning of the work is that "nature rules exist and can be found" (Stewart 1996).
Looking for nature rules we encounter a significant difficulty: we cannot investigate the whole nature - we have to explore its sections, i.e. empirical systems. However, even then it might happen that the system is too complex and its comprehensive, direct investigation is impossible. In such case we can study the system by means of its abstract model. In this paper some methodological problems associated with models and modelling, and scientific investigation by means of models will be discussed.

Many papers on modelling and models are available. This paper is performed mainly on the basis of the manual by Pabis (1985). This manual delivers basic information on empirical and abstract system models and their modelling.

\section{Basic definitions}

The empirical system is a set of objects or elements connected together with each other in different ways. The biological empirical system is an empirical system consisted 
of living forms and connections among the objects are physical connections, in which life processes occur.

The abstract system is a set of abstract objects, i.e. elements marked by sign symbols. The set has a structure made by relations or functions defined as in mathematics. In natural science the term "structure" and "process" are also used. They are equivalents for the term "system", which is defined as a dynamic system acting purposely.

Modelling can refer to: (1) model construction, i.e. a consecutive action constructing an abstract or physical model of a studied empirical system; (2) investigation of a model in order to obtain some information on a modelled empirical system.

"The idea of the model is notoriously ambiguous" therefore "according to the sense, in which the term of the model is used, models could be objects of different types" (Cackowski et al. 1987). Generally, models can be divided into abstract and material (physical) models. In this paper attention is focused mainly on abstract models, among which models informationally similar to a studied empirical system and models structurally similar to a studied empirical system are singled out.

The material or abstract structure can be accepted as a model of an empirical system if this structure is similar to the structure of a modelled system. This similarity is just what enables the replacement of a modelled empirical system by its model or models. Therefore, between the empirical system and its model (or models) a similarity relation must occur. However, the relation refers only to a similarity important from the point of scientific interest and not to a similarity per se. Hence, the similarity is always considered as a certain set of features and a set of properties.

\section{Models}

Empirical systems are composed of objects, which can be studied directly or indirectly. In the latter case, the observed phenomena i.e. empirical facts indicate their occurrence. In the indirect study of an empirical system the point is that the study of this system is performed by means of its model - an abstract system.

Abstract models made usually some simplifications in modelled empirical systems. A degree of simplification depends on different things, e.g. (1) on the purpose of a model construction or (2) on the state of our knowledge about a modelled system. As a rule we exclude from the model those variables that influence the studied variable insignificantly. Simplification does not have to mean that the heuristic validity of the simplified model will be lower than before simplification of the same model.

Different models can describe different aspects of the complex system. Such models do not have to compete among themselves, but considered from a certain point of view, one could be better than another one (Churgin 1985).

\subsection{Informationally similar abstract models}

"An information model of the empirical system is an abstract structure that can deliver numerical information on this system, although there is no similarity relation to its structure". An empirical formula, created after the investigation of a given empirical system is an example of this kind of model. In order to make empirical formulae, it is necessary to select mathematical formulae, which can replace measurement results or observations. Information models are not abstract models of scientific knowledge but applied knowledge. They can be of practical significance.

Contrary to structurally similar models, informationally similar models of empirical systems although deliver some information about these systems, they do not allow us to get to know them more profoundly and do not explain neither the structure nor the activity of these systems.

According to Pabis (1985), only structurally similar models can influence a real development of science and increase the scientific knowledge. Therefore, in his opinion, a researcher ought to prepare information models of empirical systems only then, when there is no other possibility to construct structurally similar abstract models of the studied empirical systems.

\subsection{Structurally similar abstract models}

A syntactic model is a structure made of logic or mathematical abstract symbols. Among this kind of models, there are models of formal logic, set theory or algebra. The gravitation model given by a formula $s=f(x, y)(1)$ is the syntactic model (Ackoff 1969; Pabis 1985).

We deal with the semantic model when it is possible to assign a certain empirical system to the syntactic model, i.e. when the syntactic model describes a certain empirical system. For example, if in the equation (1) the symbol $s$ means a distance covered by a freely falling object, the symbol $x$ means a gravitation value of $g$ and the symbol $y$ means a time value of $t$, then we obtain the semantic model expressed in the following way: $s=f(g, t)(2)$, which informs us that $s$ is a function of $g$ and $t$ (Ackoff 1969; Pabis 1985).

The semantic model cannot be applied yet to study indirectly the empirical system represented by this semantic model. First of all, it is necessary to find the $f$ function. It means that the semantic model must be transformed so as to be able to present results of the study of the modelled empirical system by means of numerical values. After adding a coefficient of $\frac{1}{2}$ and an index of 2 , the gravitation 
model is expressed as $s=\frac{1}{2} g t^{2}$ (3) (Ackoff 1969; Pabis

1985). In this way, the semantic model is transformed into an operational model i.e. into a structural semantic model that allows a numerical presentation of the study results of the empirical system.

Operational models of the algebraic structure are defined as mathematical models. Due to their formulation and function in the methodology and methods of empirical sciences, mathematical models can be divided into deductive and inductive models.

Deductive models are built by means of deductive inference. It is a process of deriving a conclusion that necessarily follows from given rational premises. Mathematical deductive models very seldom can be built in empirical sciences. In such a case, we have to use inductive models or, as a last resort, informationally similar models.

When the mathematical deductive model cannot be constructed but there are some empirical data at our disposal, inductive models are built. They are built by means of inductive reasoning - the process of deriving a reliable generalization from observations. This information enables a scientist to make a prediction about a structure of a studied empirical system. In practice, a subjectively selected or predicted empirical formula forms the structure of the inductive model. It means that we have to select a substantial mathematical formula e.g. exponential or power function etc., and to indicate a method of data analysis e.g. variance analysis, linear regression analysis, multiple regression analysis etc. In this place it should be stressed that the so called statistical models, which do not fulfil criteria of the empirical system's model, ought to be included in the class of empirical formulae, being at the same time information models.

Before a given inductive model is accepted, it must be empirically verified. Verification allows the estimation of an error's size, with which a model structure approximates an unknown structure of a studied empirical system as well as the applicability of this model in science.

Taking into consideration the type of numerical information, which can be delivered by operational models, we divide them into deterministic and probabilistic models. A deterministic model is a mathematical model with a structure that always assigns a unique value of $y$ to each value of $x$. A probabilistic mathematical model acts in a random way. This model has a structure that assigns more than one $y$ value to a single $x$ value.

\section{Systematic and mathematical modelling}

As it was mentioned before, operational models of algebraic structure are defined as mathematical models. Construction of mathematical models of relational and alge- braic structure is performed on the basis of systemic and mathematical modelling. The final purpose of systemic and mathematical modelling is to build a mathematical model of algebraic structure that at the same time could be an operational model of a modelled empirical system.

Systemic modelling is applied when a modelled empirical system is of very complex structure or there is no formalized empirical theory from whose laws or statements a mathematical model of a given system could logically follow. In systemic modelling a mathematical model of algebraic structure is formulated when a mathematical relational model of a modelled empirical system is ready.

In some cases, a structure of a modelled system is so simple that the systemic modelling phase can be omitted, and then we start a construction of an operational mathematical model by means of mathematical modelling methods. Pabis (1985) discussed different methods of mathematical model constructions. Many examples of mathematical modelling in biology are described by Foryś (2005). Also a classic work by Smith (1974) is worthy of attention.

\section{Knowledge - a process of scientific explanation}

Abstract models can be considered as tools to learn empirical systems and should be used expertly. According to Pabis (1985), knowledge as a process of scientific explanation of empirical systems' structures, as well as methods and effects of their activity, in the theory of knowledge it is understood as:

- a cognitive activity, i.e. a process of carrying out observations, measurements and reasoning - by means of scientific methods - in order to explain the observed facts, to draw conclusions etc.;

- an effect of a cognitive activity i.e. a process of formulating hypotheses, scientific statements and theories.

Knowledge as a cognitive activity is associated with methods of empirical sciences and psychology, because any empirical cognition is performed by means of senses. Knowledge as an effect of a cognitive activity is closely connected with methodology of empirical sciences. It should be remembered that the theory of knowledge deals with the essence of truth, as well as with sources and limits of knowledge. However, the method of solving these problems by the theory of knowledge depends on a philosophical direction on which the theory is grounded.

\section{Principles of scientific research}

Scientific research should be performed according to some rules in order to provide scientific knowledge. It is not 
so simple because terms such as science and a scientific method are defined in a different way (Bocheński 1992; Heller 1992; Chalmers 1993; Weiner 2003).

Without going into details, one can say that science is a methodical study of the objective reality. Scientific research uses a method that enables a minimization of inference errors, and causes that established facts and results obtained on the basis of these facts are intersubjectively verifiable. Methodology is a science dealing with scientific methods. It examines what methods and what way they should be applied in order to reach the aim of the study.

The scientific research does not consist in collecting, classification and ordering of observations. This kind of activities can constitute at most the introduction into heuristic studies. The basic aim of each scientific study is to recognize statistical regularities or patterns and to explain them.

The regularity always occurs when specific conditions are fulfilled. The example of this kind of regularity is the Avogadro's law: "Equal volumes of different gases, at the same temperature and pressure, contain the same number of particles or molecules". It is important to specify precisely the conditions of a recognized regularity. At present, it is difficult to indicate an ecological regularity that fulfils this requirement and probably this is the reason why the ecological regularities do not have great prognostic capacity as physical and chemical regularities do. In this respect, the publication by Palmer (1994) is an excellent illustration. Therefore, in my opinion, more attention should be paid to the detection of "strong" regularities rather than to the explanation of unconfirmed regularities of studied phenomena.

Scientific studies are reliable if a uniform terminology is applied (Wołek 1997 and literature cited there). The ideas and terms should be identically understood and interpreted by all scientists. The best would be if they were defined operationally (Ackoff 1969). It should be remembered that a scientific method ought to be based on uniform methodology and methods. If particular researchers dealing, for example, with competition use different terminology and methodology, their results will not be comparable. And then it will be difficult to find a "strong" regularity.

It was found long ago (Heller 1992) that "each observation is closely and inevitable involved in theoretical context" ("there are no naked facts"). Therefore, it should be remembered that each observation should be oriented by a certain hypothesis.

\section{References}

Ackoff R. L. with the collaboration of S. K. Gupta and J. S. Minas, 1969, Decyzje optymalne w badaniach stosowanych [Scientific method: optimizing applied research decisions], PWN, Warszawa: 539.

Bocheński J. M., 1992, Współczesne metody myślenia [Die zeitgenössischen Denkmethoden], W Drodze, Poznań: 158.

Cackowski Z., Kmita J., Szaniawski K. \& Smoczyński P. J. (eds.), 1987, Filozofia a nauka. Zarys encyklopedyczny [Philosophy and science. An encyclopaedic outline], Zakład Narodowy Ossolińskich, Wrocław: 789.

Chalmers A. F., 1993, Czym jest to, co zwiemy nauką? [What is this Thing called Science], Siedmioróg, Wrocław: 216.

Churgin J., 1985, Jak policzyć niepoliczalne [How uncountable can be counted], Wiedza Powszechna, Warszawa: 227.

Foryś U., 2005, Matematyka w biologii [Mathematics in biology], Wydawnictwa Naukowo-Techniczne, Warszawa: 256.

Heller M., 1992, Filozofia nauki. Wprowadzenie [Philosophy of science. Introduction], Wydawnictwo Naukowe Papieskiej Akademii Teologicznej, Kraków: 92.

Pabis S., 1985, Metodologia i metody nauk empirycznych [Methodology and methods of empirical sciences], PWN, Warszawa: 267.

Palmer M. W., 1994, Variation in species richness: towards a unification of hypotheses, Folia Geobotanica et Phytotaxonomica (Praha) 29: 511-530.

Smith J. M., 1974, Matematyka w biologii [Mathematical ideas in biology], Wiedza Powszechna, Warszawa: 208.

Stewart I., 1996, Czy Bóg gra w kości? Nowa matematyka chaosu [Does God play dice? The new mathematics of chaos], PWN, Warszawa: 366.

Weiner J., 2003, Życie i ewolucja biosfery [Life and evolution of the biosphere], Wydawnictwo Naukowe PWN, Warszawa: 609.

Werle J., 1992, Jedność przyrody: rzeczywistość czy iluzja [Integrity of the nature: reality or illusion], Zakład Narodowy im. Ossolińskich, Wrocław-Warszawa-Kraków, Seria Problemy Naukowe Współczesności: 57.

Wołek J., 1997, Species co-occurrence patterns in pleustonic plant communities (class Lemnetea): are there assembly rules governing pleustonic community assembly?, Fragmenta Floristica et Geobotanica Supplementum 5: 3-100. 